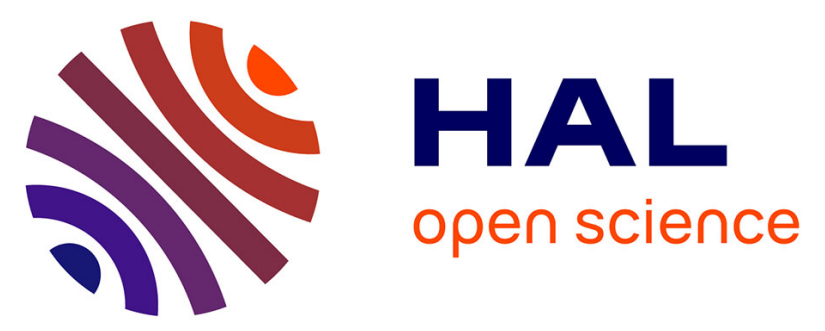

\title{
HIGH RESOLUTION ELECTRON BEAM INJECTION IN SEMICONDUCTORS USING A SCANNING TUNNELING MICROSCOPE
}

S. Alvarado, Ph. Renaud, H. Meier

\section{- To cite this version:}

S. Alvarado, Ph. Renaud, H. Meier. HIGH RESOLUTION ELECTRON BEAM INJECTION IN SEMICONDUCTORS USING A SCANNING TUNNELING MICROSCOPE. Journal de Physique IV Proceedings, 1991, 01 (C6), pp.C6-271-C6-275. 10.1051/jp4:1991641 • jpa-00250727

HAL Id: jpa-00250727 https://hal.science/jpa-00250727

Submitted on 1 Jan 1991

HAL is a multi-disciplinary open access archive for the deposit and dissemination of scientific research documents, whether they are published or not. The documents may come from teaching and research institutions in France or abroad, or from public or private research centers.
L'archive ouverte pluridisciplinaire HAL, est destinée au dépôt et à la diffusion de documents scientifiques de niveau recherche, publiés ou non, émanant des établissements d'enseignement et de recherche français ou étrangers, des laboratoires publics ou privés. 


\title{
HIGH RESOLUTION ELECTRON BEAM INJECTION IN SEMICONDUCTORS USING A SCANNING TUNNELING MICROSCOPE
}

\author{
S.F. ALVARADO, Ph. RENAUD and H.P. MEIER
}

IBM Research Division, Zurich Research Laboratory, Säumerstr. 4, CH-8803 Rüschlikon, Switzerland

\begin{abstract}
The tip of a scanning tunneling microscope is used as a source of ultralow-energy electrons to excite luminescence in model AIGaAs/GaAs(001) heterostructures. This beam injection technique has the advantage of providing a nanometer-sized charge generation volume. We demonstrate the application of this technique to determine minority charge carrier transport parameters such as the thermalization length of hot electrons and the diffusion length of minority electrons.
\end{abstract}

\section{Introduction}

The tip of an scanning tunneling microscope (STM) can be used as a source of charge carriers to excite light emission in semiconductors [1]. This excitation mode allows luminescence to be induced within single quantum wells of dimensions down to a few nanometers [1] and to determine the position of conduction bands [2]. Furthermore the high lateral resolution achieved with the electron beam injected into the semiconductor's surface region allows the conduction band discontinuity as well as the profile of the band bending at GaAlAs/GaAs interfaces to be probed directly with a transversal resolution of $1.5 \mathrm{~nm}$ [3]. In Ref. 2 we proposed that the STM-excited luminescence be used as a new way to determine minority charge carrier transport parameters such as the thermalization length of hot electrons and the diffusion length of minority electrons. In this note we present a more detailed discussion as well as results. An important characteristic of the STM beam injection technique is that electrons can be injected at energies of a few electron volts. Therefore the radius of the source is determined by the thermalization length of hot electrons which is only a few nanometers. Furthermore this source is located within a few nanometers of the free surface. This is to be compared with excitation by means of an electron beam of several kilo-electron volts as for example in a SEM-EBIC experiment, where the range and the radius of the electron-hole pair generation volume is of the order of 0.1 to $1 \mu \mathrm{m}$. The improvement of resolution achievable with the "STM-EBIC" opens a new possibility to determine directly the thermalization length of hot carriers. It should be noted that for some values of the tunneling voltages used in the STM experiments the electron energy might lie well below the carrier pair excitation energy. 


\section{Experimental}

The $\mathrm{Al}_{0.38} \mathrm{Ga}_{0.62} \mathrm{As}$ heterostructure was grown by MBE on $\mathrm{GaAs}(001)$ substrates. The STM experiments were performed at $T=300 \mathrm{~K}$ in an apparatus operating near or below the $10^{-10}$ Torr pressure range. Samples and tips can be introduced into the apparatus by means of an air lock. The tips are made of electrochemically etched $\mathrm{Ni}$ wire and cleaned by $\mathrm{Ne}$-ion bombardment in the UHV chamber. Clean AIGaAs(110) surfaces were obtained by cleaving thinned sample coupons in situ. Luminescence is excited by tunneling in the constant current mode at negative tip voltages. By using a suitable radiation filter in front of the photomultiplier tube, only radiation due to recombination within the GaAs quantum wells is detected. For more experimental details see Ref. 2. The part of the heterostructure used for probing the minority carrier transport consists of two GaAs wells separated by $1 \mu \mathrm{m}$ of $\mathrm{Al}_{0.38} \mathrm{Ga}_{0.62} \mathrm{As}$. The structure is Be-doped at $10^{19} \mathrm{~cm}^{-3}$. The STM-excited luminescence measurements are performed by tunneling on the (110) plane produced by cleavage, i.e. the electrons are injected in a direction parallel to the GaAs/AlGaAs interfaces, see Fig. 1.

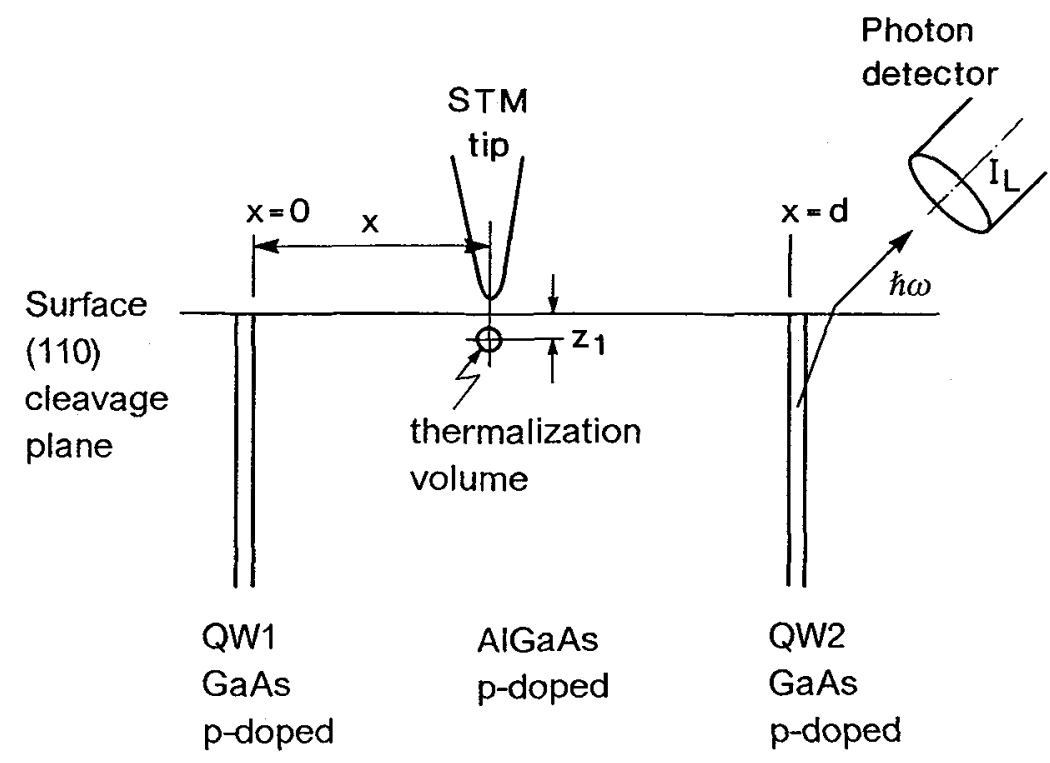

Fig. 1. Schematics of the STM-excited luminescence setup used to characterize the transport properties of charge carriers in a GaAsAl heterostructure.

\section{Results and Discussion}

In the STM-excited luminescence measurement the quantum wells QW1 and QW2 act as current collectors. We can safely assume that the luminescence intensity $I_{L}$ is linearly proportional to the current reaching a given quantum well $I_{\mathrm{SC}}$, i.e. 


$$
I_{\mathrm{L}}=\mathrm{Q}_{\mathrm{i}} I_{\mathrm{SC}}
$$

where $Q_{i}$ is the luminescence efficiency of a given quantum well. Since both quantum wells contribute, the observed light intensity is proportional to the sum of the current reaching each quantum well. Figure 2 shows luminescence profiles collected at various tunneling voltages $V_{T}$ as a function of distance $x$ between the apex of the tip and the right GaAs/AlGaAs interface of the left quantum well QW1. Maximum luminescence intensity is observed when tunneling directly into the well, i.e. for $-w<x<0$. As the tip crosses the interface $x=0$ into the $\mathrm{Al}_{0.38} \mathrm{Ga}_{0.62} \mathrm{As}$ a sharp decrease in intensity occurs. The exponential decay length of this initial steep intensity decrease is energy-dependent, increasing with the magnitude of $V_{T}$, and can thus be related to the thermalization length of hot electrons. The energy of the electrons injected into the surface region is

$$
E_{\mathrm{k}}=e V_{\mathrm{T}}-E_{\mathrm{G}}
$$

where $E_{\mathrm{G}}$ is the forbidden band gap of $\mathrm{Al}_{0.38} \mathrm{Ga}_{0.62} \mathrm{As}, E_{\mathrm{G}}=1.96 \mathrm{eV}$. Since a sizable band-bending of up to $\delta=0.7 \mathrm{eV}$ can appear at the AlGaAs surface, even though working in the extremely clean UHV conditions $[2,4]$ the actual kinetic energy of the injected electrons within the depletion region is higher than that given in Eq. (2) above. We find

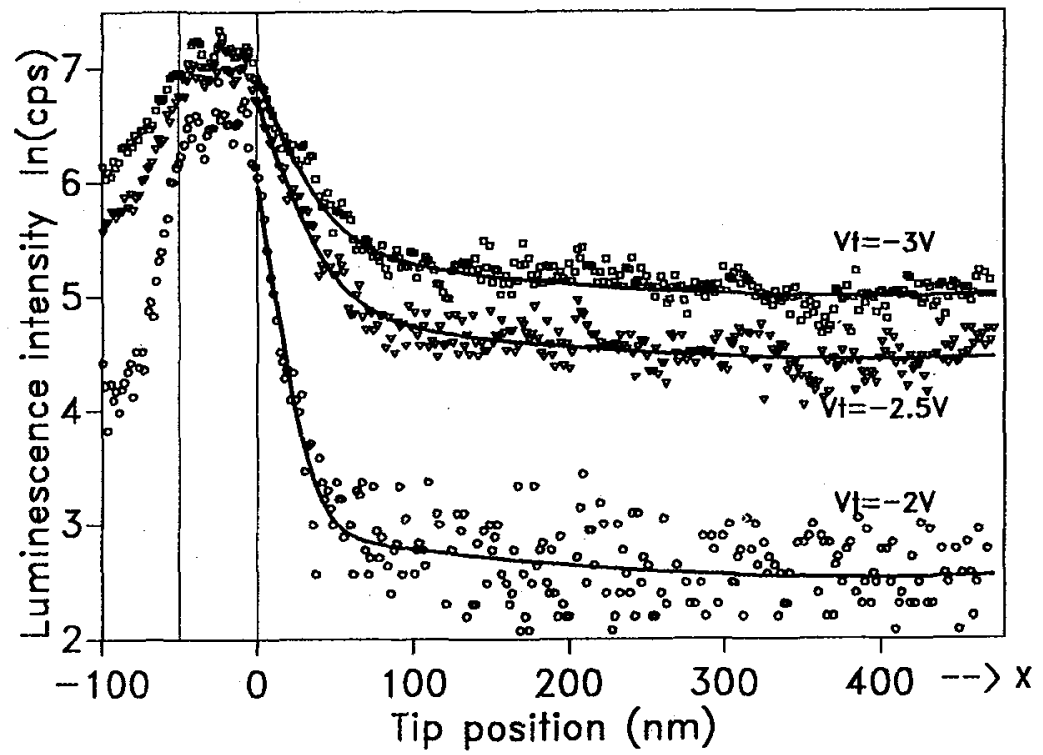

Fig. 2. Luminescence intensity profile near a $50 \mathrm{~nm}$ quantum well separated by $1 \mu \mathrm{m}$ $\mathrm{Al}_{0.38} \mathrm{Ga}_{0.62} \mathrm{As}$ from another quantum well. The solid lines represent the curves fitted to the data to obtain the minority carrier thermalization length and the diffusion length at different tunneling voltages. The values used are $\ell_{\text {th }}=14,25$ and $29 \mathrm{~nm}$ for $V_{T}=-2.0,-2.5$ and $-3.5 \mathrm{~V}$ respectively and $L_{D}=450 \mathrm{~nm}$. 
exponential decay lengths of $\ell_{\mathrm{th}} \simeq 14 \mathrm{~nm}$ for $V_{\mathrm{T}}=-2.0 \mathrm{~V}, \ell_{\mathrm{th}} \simeq 25 \mathrm{~nm}$ for $V_{\mathrm{T}}=-2.5 \mathrm{~V}$, and $\ell_{\text {th }} \simeq 29 \mathrm{~nm}$ for $V_{T}=-3.5 \mathrm{eV}$. This value of $\ell_{\text {th }}$ corresponds very well to energy losses due to optical phonons of energy of $36 \mathrm{meV}$ and a mean scattering length of 4.3 $\mathrm{nm}$ [5]. Following the steep decrease due to thermalization a region exhibiting a much longer characteristic decay length is observed. This we interpret to be the drift region, where minority carriers diffuse towards the well after thermalization. The functional form $I_{\mathrm{SC}}(x)$ of the current collected at one of the planes for a system limited by two planes, $\mathrm{p} 1$ and p2, perpendicular to a free surface has been calculated by Von Roos [6]. For the case of an isotropic point source close to the surface and under the assumption that the collector $\mathrm{p} 1$ and the plane $\mathrm{p} 2$ are both perfect current sinks, and that the surface recombination $S_{s}$ can be neglected the functional form is:

$$
I_{\mathrm{SC}}(x) \propto \sinh \left(\frac{d-x}{L_{\mathrm{D}}}\right)
$$

where $d$ is the distance between the planes $p 1$ and $p 2$, and $x$ is the distance between $p 1$ and the point source of minority carriers, and $L_{D}$ is the minority carrier diffusion length. For our sample $\mathrm{p} 1$ and $\mathrm{p} 2$ correspond the interfaces of the quantum wells $\mathrm{QW} 1$ and $\mathrm{QW} 2$ in contact with the AIGaAs slab. Since both quantum wells contribute to the signal we have. using Eq. (1)

$$
I_{L}(x) \propto \sinh \left(\frac{x}{L_{D}}\right)+\sinh \left(\frac{d-x}{L_{D}}\right)
$$

where it is assumed that the efficiency of both quantum wells is equal. The above equation can be conveniently simplified:

$$
I_{L}(x) \propto \cosh \left(\frac{2 x-d}{2 L_{D}}\right) .
$$

The value of $L_{D}$ can then be determined by fitting the above equation to the data. The solid line in Fig. 2 represents the best fit and includes the exponential function fitted to the decay due to thermalization into the quantum wells near the interface. The best fit is obtained for $L_{D}=450 \pm 50 \mathrm{~nm}$. This is compared to the value $L_{D} \simeq 2.5 \mu \mathrm{m}$, reported by Zarem et al. [7] for $\mathrm{Al}_{0.37} \mathrm{Ga}_{0.63} \mathrm{As}$ at $p$-doping levels in the range $10^{-17}$ to $10^{-18} \mathrm{~cm}^{-3}$. Our markedly smaller value is not a sign of discrepancy but rather is explained by the higher doping level of our sample. Thus, in GaAs the diffusion length decreases roughly by a factor of four upon increasing of the $p$-doping level from $10^{-18}$ to $10^{-19} \mathrm{~cm}^{-3}[8]$. We note that the magnetic field exerted by the tip (max. $0.6 \mathrm{~T}$ ) could give rise to an apparent reduction of the diffusion length owing to Lorenz forces [9]. The diffusion length determination depends critically on the boundary conditions at the surface of the sample. In the present analysis we assume that the surface recombination velocity is negligible. This is plausible if one considers that the experiment was performed on clean surfaces produced in UHV. Much higher surface recombination velocities are expected if the samples are exposed to air, i.e. oxidation and surface contamination, which can certainly induce numerous surface defects promoting surface recombination. In such cases the surface recombination velocity is comparable to the diffusion velocity of minority carriers 
[10]. In UHV conditions the number of defects and thus the surface recombination is certainly greatly reduced. These considerations are further supported by the fact that if $S_{\mathrm{s}}=\infty$ is assumed we find that, fitting the data to a proper function [6], the fitted values of the diffusion length become excessively large. It would be interesting to modify the surface of the samples in UHV to study the effects on the surface recombination.

\section{Conclusions}

We have shown that the STM provides a high-resolution beam injection technique capable of probing the charge carrier transport of hot and thermalized electrons in heterostructures consisting of epitaxial layers of thickness comparable to the diffusion length of the carriers. Using a model III-V heterostructure we determine the thermalization length of electrons of $E_{k}=1$ and $1.5 \mathrm{eV}$. The diffusion length was determined to be $L_{D}=450 \pm 50 \mathrm{~nm}$ in $\mathrm{Al}_{0.38} \mathrm{Ga}_{0.62} \mathrm{As}$ Be-doped at $10^{19} \mathrm{~cm}^{-3}$. The surface recombination velocity in the UHV-produced (110) surface of the sample appears to be negligible. This would mean that only a small fraction of the current tunneling to the surface is absorbed at the surface. This is at best the case when the surface is well ordered and clean. The STM luminescence can also be excited in $n$-doped semiconductors $[1,11]$, and the transport properties of holes in $n$-doped $\mathrm{GaAs} /\left(\mathrm{Al}_{0.7} \mathrm{Ga}_{0.3}\right)_{0.5} \mathrm{In}_{0.5} \mathrm{P}$ heterostructures can also be characterized by this technique [12]. In addition STM-excited luminescence opens up new possibilities for performing local spectroscopic characterization of semiconductors and devices - including the possibility of studying surface states and single trapping centers associated with lattice defects, impurities, and chemisorbed species at the surface [1].

\section{Acknowledgements}

We are very thankful to A. Jakubowicz for many fruitful discussions. Many thanks are also due to $H$. Richard and L. Perriard for help in scribing the samples to obtain high-quality cleavages.

\section{References}

[1] D.L. Abraham, A. Veider, Ch. Schönenberger, H.P. Meier, D.J. Arent, and S.F. Alvarado, Appl. Phys. Lett. 56 (1990) 1564

[2] S.F. Alvarado, Ph. Renaud, D.L. Abraham, Ch. Schönenberger, D.J.Arent, and H.P. Meier, J. Vac. Sci. Technol. B9 (1191) 409

[3] Ph. Renaud and S.F. Alvarado, Phys. Rev. B in press

[4] O. Albrektsen, D.J. Arent, H.P. Meier, and H.W.M Salemink, Appl. Phys. Lett. 57 (1990) 31; H. Salemink and O. Albrektsen, J. Vac. Sci. Technol. B9 (1991) 779

[5] cf. for instance H. Kressel and G. Kupski, J. Electron. 20 (1966) 535; M. Haas and B.W. Henvis, J. Phys. Chem. Solids 23, (1962) 1099

[6] O. Van Roos, Solid State Electronics Vol. 21 (1978) 1063; idem. J. Appl. Phys. 54, (1083) 3938

[7] H.A. Zarem, P.C. Sercel; J.A. Lebens, L.E. Eng, A. Yariv, and K.J. Vahala, Appl. Phys. Lett. 55, 1647 (1989); H.A. Zarem, J.A. Lebens, K.B. Nordstrom, P.C. Sercel, L.E. Eng, A. Yariv, and K.J. Vahala, Appl. Phys. Lett. 55 (1989) 2622

[8] L.D. Partain, M.S. Kuryla, L.M. Fraas, P.S. McLeod, and J.A. Cape, J. Appl. Phys. 61 (1987) 5150; S. Tiwari and S.L. Wright, Appl. Phys. Lett. 56 (1990) 563

[9] Wada, A. Kozen, H. Fushimi, and N. Inoue, Jpn. J. Appl. Phys. 27, 1952 (1988)

[10] M. Ettenberg, H. Kressel, and S.L. Gilbert, J. Appl. Phys. 44 (1973) 827

[11] R. Berndt, R.R. Schlittler, and J.K. Gimzewski, J. Vac. Sci. Technol. B9 (1991) 573

[12] Ph. Renaud, S.F. Alvarado and P. Roentgen, to be published 